\title{
XXXVI. On the theory of parallel lines in geometry
}

\author{
James Ivory M.A. F.R.S.
}

To cite this article: James Ivory M.A. F.R.S. (1822) XXXVI. On the theory of parallel lines in geometry, Philosophical Magazine Series 1, 59:287, 161-167, DOI: $10.1080 / 14786442208652710$

To link to this article: http://dx.doi.org/10.1080/14786442208652710

曲 Published online: 29 Jul 2009.

Submit your article to this journal $\pi$

LII Article views: 3

Q View related articles $\sqsubset$ 
XXXVI. On the Theory of parallel Lines in Genmetry. By JaMES I VORY, M.A. F.R.S.

IN laying down the elements of mathematical science, great difficulties occur at the outset. In arithmetic we are immediately embarrassed with the doctrine of incommensurable quantities. In geometry, the manner of treating the subject of parallel lines is a blemish which the efforts of ancient and modern mathematicians have equally failed to remove. In the same science some obscurity and even mistakes prevailed with respect to the equality of solid figures, till accuracy and precision were introduced by the publication of Legendre's Elements, one of the ablest and most original works that has appeared in modern times. The comparison of the pyramid with the prism must also have occasioned some perplexity to the first authors who wrote on geometry, In advancing further, new difficulties occur at cvery step; as when we would compare the lengths of curve and straight lines; or when we would determine the proportion between curve and plane surfaces.

In algebra some obscurity has arisen from what are called negative quantities. But it would be very inaccurate to assimilate the seeming paradoxes and apparent contradictions that arise from the doctrine of negative quantities in algebra to the real difficulties that are met with in geometry. The latter are unavoidable, and inherent in the subject : the former originate from inaccurate phraseology, and the crude and umphilosophical manner of treating the elements of a branch of science comparatively new, and that, in no great space of time, has been almost immeasurably extended. There can be no better argument for the truth of what is here advanced, than to observe that the absurdities attending the use of the negative sign appear only in general discussione, and when the quantities affected with it are considered abstractly. It is only on such occasions that we hear of quantities less than nothing; or that negative quantities are compared to debts, while positive quantities signify real possessions. These exceptionable modes of speaking are never introduced in the solution of particular problems. In such cases all the relations of the quantities considered are distinctly comprehended, and the algebraist readily accomplishes his purpose by means of addition, and the no less clear operation of subtracting a less from a greater quantity. It is with these clear notions that the mind, in every investigation, sets out; and the difficulty consists in reconciling them with the generalizations not only permitted but required by the genius of algebra.

Vol. 59. No. 287. March 1322. 
Some mathematicians of this country, founding their objections chiefly on verbal inaccuracies, contend that the doctrine of negative quantities should be banished from algebra. Without stopping to inquire into the cause of the obscurities of which they complain, these purists will give no quarter to any thing that has even the appearance of infringing the clenrness and evidence which is the boast of mathematical scietice. They rather choose to obviate the difficulties they meet with, by breaking down every proposition into its particular cases, than, by following the spirit of the algebraic analysis, to comprehend them all in one investigation. In order to obtain the same clearness in algebra for which the ancient geometry is admired, they would neglect the distinction between the two sciences, and would cramp the former by the restrictions to which the latter is necessarily subject.

In geometry every proposition, even the most general, is demonstrated with reference to a particular diagram. In the $47 \mathrm{th}$ of the first book of Euclid, all the reasoning is directed to the particular triangle represented in the scheme. But as no part of the demonstration depends upon any peculiar relations of the sides or angles of that triangle, it is clearly seen that the property proved will belong to any one of the same species. In the instance now mentioned there are uo subordinate cases that require an alteration of the diagram. But as one geometrical figure can properly represent all those only that are exactly similar to it, it often happens that the different cases of the same proposition require several diagrams, to each of which a separate demonstration must be applied. The genmeter may perceive a great similitude between the subordinate cases; insomuch that, when one is understood, all the rest are reardily deduced from it ; but the science he cultivates furtushes no method of bringing the observed analogy under precise and general rules. A geometrical demonstration is never deemed complete, unless all the cases be fully enumerated, and separately investigated.

The algebraist can no more translate a problem from the common into the analytical language, without conceiving a particular state of the quantities concerned, than the geometer can demonstrate without reference to a particular diagram. But when an equation has been obtained from one particular case, it necessarily comprehends under it every possible case of the same problem. In algebra there can be no variation in the state of a problem excepting as the quantities concerned are greater or less. If the quantity sought he greater than some known quantity, an addition is implied ; if less, we must conceive a subtraction. But au equation obtained on the first hypothesis, applies 
to the second, by the substitution of a negative in place of a positive quantity; that is, merely by changing the signs of some of the terms; which changes are made not in an arbitrary manner, but by fixt rules derived from the mechanism of analytical language. This conclusion was not perhaps perceived in all its extent by the first algebraists, but it has been firmly established in the progress of the science, and is indeed a necessary consequence of the general rules about which all are agreed. It is in this manner that an algebraic expression, the structure of which remains essentially the same, adapts itself to all the possible cases of a problem, while in geometry the same cases are only connected by a vague similarity not reducible to precise rules. When an equation is solved, the result may either be positive, that is, a quantity to be added ; or it may be negative, that is, a quantity to be subtracted; but in both cases the meaning is equally clear when we go back to the primitive hypothesis, and consider the algebraic signs as notes of reference to the different views that may be taken of the same problem.

Algebra therefore, by means of the doctrine of negative quantities, possesses a great advantage over geometry. In the former science, a problem is comprehended in one expression capable of adapting itself, by the regular changes it admits of, to every particular case; in the latter, all the subordinate cases remain detached, and must be separately considered. By the comprehensive spirit of the first science, the investigation of truth is shortened and facilitated. Nor does it necessarily follow that the generalizations of algebra must be attended with obscurity. It may be affirmed that the ideas of the algebratist are clear in many instances where, by using the language of his predecessors, he has expressed himself in terms the most exceptionable.

The mathematicians, who would reject negative quantities, woukd introduce into algebra the procedure, necessarily followed in geometry, of minutely subdividing every proposition into all its particular cases. By this means no doubt the same clearness would be obtained in the one science which is so commendable in the other; but at the same time algebra wouid be stript of its greatest and most peculiar excellence as an instrument for the investigation of truth. What the purists recommend is, in reality, to cut the knot of the diffeulty, in order to avoid the trouble of unravelling it. The projer remedy seems to be, to mount up to the cause of the imperfections complained of, and by an enlarged view of the nature and scope of the science, to preserve all the generality of which it is capable, at the same time that its rules are deduced with the evidence required in mathematical reasoning. 
But, to retuin to geometry, it may be worth while to inquire, what has been the conduct of the ancients in regard to the difficulties that present themselves in that science. They have either overcome the obstacles that obstructed their progress; or, when this was impossible, they have fairly laid down what they could not demonstrate as principles to be assented to by their disciples in the further prosecution of their researches. Of the first of these ways of proceeding we have instances in the investigations relating to incommensurable yuantities, and to the proportion between the pyramid and the prism. In both these cases too the ancient geoneters have succeeded by the same means, namely, by employing the indirect mode of investigation.

Archimedes furnishes an example of the other way of proceeding in the principles prefixed to his treatise on the Sphere and Cylinder. These principles, on which are founded the most considerable of his discoveries in pure mathematics, are really theorems which ought to be demonstrated, but which the ancient geometry affords no means of proving. Another instance of the same kind we have in Euclid's manner of treating parallel lines. That geometer has demonstrated, in the 17 th of the first book, that any two angles of a triangle are togetber less than two right angles. The plan of his work required that the converse of the same proposition should be proved; and it is the want of this proof, which no geometer has been able to invent, that constitutes the difficulty in the theory of paraliel lines. Euclid has therefore, in the 12 th Axiom, laid down, as a principle to which the assent is demanded, the proposition of which no demonstration can be found. It is no doubt inaccurate to class a principle of this kind with the axioms to which it has no affinity; but this is an objection of no moment, when the intention of the anthor is understood.

Many attempts have been made by succeeding geometers to remove the defect found in Euclid's doctrine of parallel lines. New definitions of the straight line have heen imagined; and new axioms, or rather new principles of reasoning, have been proposed; but none of these expedients have been attended with complete success. On a deliberate view of the case the preference must, I think, be given to Euclid's manner of treating the subject; because it places hefore the student without disguise the true nature and origin of the difficulty.

Legendre, in the first nine editions of his Geometry, has treated parallel lines in a manner that is both new and seems to be more intimately connected with the real cause of the difficulty than any other hitherto proposed. The foundation of it is to prove, 
independently of the theory of parallels, that the three angles of a triangle are together equal to two right angles. This is accomplished by proving indirectly that the angles of a triangle can neither be less nor greater than two right angles. And, when we reflect that the whole difficulty is occasioned by the imperfect nature of the definition of a straight line, we are led to suspect that it is necessary to employ the indireet mode of reasoning. One objection may be made to Legendre's demonstration; for we are required to admit that, through a point situated within a rectilineal angle, at least one straight line may be drawn that shall meet both the sides of the angle; a hypothesis, which, although it be very probable, is yet in some degree uncertain and precarious. Thinking to gratify the lovers of speculative geometry, I shall now add a denonstration of the same proposition, which requires no new principles, and is liable to no objection excepting the length that always attends indirect investigations.

\section{Prop. I. Fig. 5 (Plate III.)}

To construct a triangle that shall have the sum of its angles equal to the sum of the angles of a given triangle, and one of its singles equal to, or less than, half any proposed angle of the given triangle.

Let $A B C$ be the given triangle, and $\triangle B C$ one of its angles : bisect the side $\mathrm{AC}$, opposite to $\mathrm{ABC}$, in $\mathrm{E}$; join $\mathrm{BE}$, and, having produced it, cut off $E F$ equal to $B E$; join $C F$ : the sum of the angles of the triangle $\mathrm{B} \mathrm{FC}$ will be equal to the sum of the angles of the triangle $A B C$; and one of the angles F BC or BFC will be equal to, or less than, half the angle A B C.

The construction being the same as in the 16 th of the first book of Euclid, it may be prover, as in that proposition, that the two triangles $A E B$ and $C E F$ are equal in all respects. Wherefore, the angle $\mathrm{BAE}$ being equal to $\mathrm{ECF}$, the whole angle $B C F$ is equal to the tivo angles $B A E$ and $B C E$; and, the angle $A B E$ being equal to $\mathrm{EFC}$, the whole angle $\mathrm{ABC}$ is equal to the two angles $\mathrm{CBE}$ and $\mathrm{EFC}$. Consequently the three angles $B C F, C B E$, and $E F C$ are equal to the three angles $B A C, A C B$, and $A B C$. Again, if $B C$ be equal to $\mathrm{CF}$, the angles $\mathrm{EBC}$ and $\mathrm{EFC}$ will be equal to one another, and to the half of $\mathrm{ABC}$; but, if $\mathrm{BC}$ and $\mathrm{CF}$ be unequal, the angles $\mathrm{E} \mathrm{BC}$ and $\mathrm{EFC}$ will likewise be unequal, and one of them will be less than the half of $A B C$.

This proposition may be considered as a corollary to the 16 th of the first book of Euclid. 


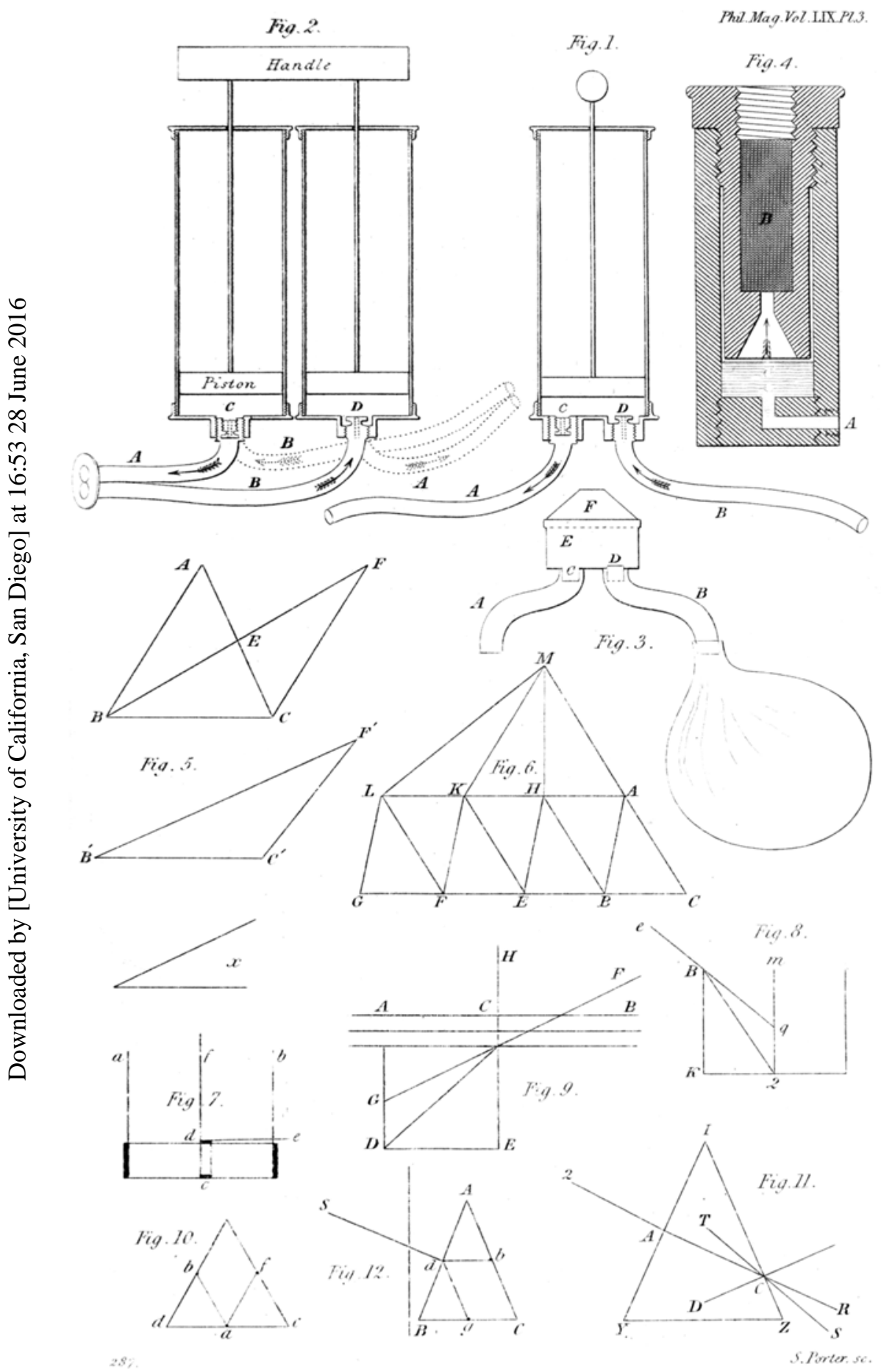




\section{Prop. 1I. Fig. 5.}

The threc angles of a triangle cannot be greater than two right angles.

If it be possible, let the three angles of the triangle $\mathrm{A} \mathrm{B} \mathrm{C}$ be greater than two right angles, and let the excess above two right angles be equal to the angle $x$. Construct the triangle $\mathrm{BCF}$, having the sum of its angles equal to the sum of the angles of the triangle $A B C$, and one angle $F B C$ equal to, or less than, half the angle $A B C$; in like manner, construct another triangle $\mathrm{F}^{\prime} \mathrm{B}^{\prime} \mathrm{C}^{\prime}$ having the sum of its angles equal to the sum of the angles of the triangle $\mathrm{F} \mathrm{BC}$, and one angle $\mathrm{F}^{\prime} \mathrm{B}^{\prime} \mathrm{C}^{\prime}$ equal to, or less than, half the angle $\mathrm{FBC}$; and continue the like constructions as far as necessary. Because the angle $\mathrm{F} B \mathrm{C}$ is equal to, or less than, half $\mathrm{ABC}$; and the angle $\mathrm{F}^{\prime} \mathrm{B}^{\prime} \mathrm{C}^{\prime}$, equal to, or less than, half $\mathrm{FBC}$, and so on; by continuing the series of triangles far enongh. we shall at length arrive at one, viz. $\mathrm{F}^{\prime} \mathrm{B}^{\prime} \mathrm{C}^{\prime}$, having an angle $\mathrm{F}^{\prime} \mathrm{B}^{\prime} \mathrm{C}^{\prime}$ less than the given angle $x^{*}$. And because the three angles of every triangle in the series make the same sum, the three angles $B^{\prime} C^{\prime} F^{\prime}, B^{\prime} F^{\prime} C^{\prime}, F^{\prime} B^{\prime} C^{\prime}$ will be together equal to the sum of two rigbt angles and the angle $x$ : but the angle $F^{\prime} B^{\prime} C^{\prime}$ is less than the angie $x$; wherefore the angles $\mathrm{B}^{\prime} \mathrm{C}^{\prime} \mathrm{F}^{\prime}$ and $\mathrm{B}^{\prime} \mathrm{F}^{\prime} \mathrm{C}^{\prime}$ are greater than two right angles; which is absurd (17.1.E.) Therefore the three angles of a triangle cannot bo greater than two right angles.

The following demonstration does not fall off from the accuracy and spirit of the ancient geometry, althongh, for the sale of brevity, it is not dressed out in the usnal costume.

\section{Prop. III. Fig. 6.}

The three angles of any triangle are equal to two right angles.

If what is affirmed be not true, let the three angles of the triangle $\mathrm{ACB}$ be less than two right angles, and let the defect from two right angles be equal to the angle $x$. Let $\mathrm{P}$ stand for a right angle, and find a tnultiple of the angle $x$, viz. $m \times x$, such that $4 P-n \times x$, or the excess of four right angles above the multiple angle, shall be less tban the sum of the two angles A C B and $A B C$ of the proposed triangle. Produce the side $C B$, and cut off $B E, E F, F G, 8 c$. each equal to $B C$, so that the whole $\mathrm{CG}$ sholi contain $C, B \mathrm{~m}$ times; and construct the triangles BHE, EKF, FLG, \&c., having their sides equal to the sides of the triangle $\triangle \mathrm{CB}$, and consequently, their angles equal to the angles of the samie triangle. In $\dot{\mathrm{C}} \mathrm{A}$ producerl, take any point M, and draw HM, KM, LM, \&c.; A H, HK, KL, \&c.

All the angles of all the triangles into which the quadrilateral

* For by continually hisecting any proposed magnitude, a marnitude vill at length be found less that any given magnitude. 
figure CGL M is diwided, constitute the four angles of that figure, together with the angles round each of points $\mathrm{H}, \mathrm{K}, \mathrm{\& c}$., and the angles, directed into the interior of the figure, at the points $A, B, E, F, \& c . \quad B u t$ all the angles round the points $H, K, \& c$, of which points the number is $m-2$, are equal to $(m-2) \times 4 \mathrm{P}$, or to $4 \mathrm{mP}-8 \mathrm{P}$; and all the angles at the points $\mathrm{A}, \mathrm{B}, \mathrm{E}, \mathrm{F}$, $\& c$, are equal to $m \times 2 \mathrm{P}$. Wherefore the sum of all the angles of all the triangles into which the quadrilateral C GLM is dividerl, is equal to the four angles of that figure together with $4 m \mathrm{P}^{\mathrm{P}}-8 \mathrm{P}+2 m \mathrm{P}=6 m \mathrm{P}-8 \mathrm{P}$.

Again: the three angles of the triangle A B C are, by the hypothesis, equal to $2 \mathrm{P}-x$; and, as the number of the triangles $\mathrm{CAB}, \mathrm{BHE}, \mathrm{EKF}, \mathrm{FL} G$ is equal to $m$, the sum of all the angles of all these triangles, will be equal to $2 m \mathrm{P}-m \times x$. Upon each of the lines $A \mathrm{H}, \mathrm{HK}, \mathrm{KL}$, there stand two triangles, one above and one below; and, as the three angles of a triangle caninot exceed two right angles, it follows that all the angles of those triangles, the number of which is equal to $2 m-2$, cannot exceed $4 m \mathrm{P}-4 \mathrm{P}$. Wherefore the sum of all the angles of all the triangles into which the quadrilateral C GML is divided, cannot exceed $4 m \mathrm{P}-4 \mathrm{P}+2 m \mathrm{P}-m \times x=6 m \mathrm{P}-8 \mathrm{P}+$ $4 \mathrm{P}-m \times *$.

It follows, from what has now been proved, that the four angles of the quadrilateral C GL M, together with $6 m \mathrm{P}^{2}-8 \mathrm{P}$, cannot exceed $6 m \mathrm{P}-8 \mathrm{P}+4 \mathrm{P}-m \times x$. Wherefore, by taking the same thing, viz. $6 m \mathrm{P}-8 \mathrm{P}$, from the two unequal things, the four angles of the quadrilateral CGLM cannot exceed $4 \mathrm{P}-m \times x$. But $4 \mathrm{P}-m \times x$ is less than the sum of the two angles $A C B$ and $A B C$, or than the sum of the two angles $A C B$ and $L C F$ : wherefore, a fortiori, the four angles of the quadrilateral cannot exceed the sum of the two angles $A C B$ and LGF; that is, a whole camot esceed a part of it ; which is absurd. Therefore the three angles of the triangle $\mathrm{ABC}$ cannot be less than two right angles.

And liecause the three angles of a triangle can neither be greater nor less than two right angles, they are equal to two right angles.

By the help of the proposition just proved, the defect in Euclid's Theory of parallel Lines may be removed, as the reader will see by consultiug the notes to Professor Playfair's Elements of Geometry.

Legeudre has demonstrated the same proposition in a different manner, by means of algebraic functions. The like mode of reasoning has also been applied to elementary propositions in other branches of science; particularly to the composition of forces in mechanics. The evidence of such demonstrations may, on another occasion, become the subject of inquiry.

March 6, 182?.

J. Ivory. 